\title{
Simultaneous Nitrification and Denitrification Associated Phosphorus Uptake Properties of Sludge Subjected to EBPR with Efficient Micro Aeration
}

\author{
Juan $\mathrm{Ma}^{1, \mathrm{a}^{*}}$, Xiaojun $\mathrm{Yu}^{1}$, Lu Song ${ }^{1}$, Hongwei Sun ${ }^{1}$, Daniel R. Noguera ${ }^{2}$ \\ ${ }^{1}$ Department of Environmental Engineering, School of Environmental and Municipal Engineering, \\ Lanzhou Jiaotong University, Lanzhou Gansu 730070, China. \\ ${ }^{2}$ Department of Civil and Environmental Engineering, University of Wisconsin, Madison WI 53706, \\ USA. \\ ameggyma@163.com
}

Keywords: Enhanced biological phosphorus removal (EBPR); simultaneous nitrification and denitrification; micro aeration

Abstract: Simultaneous nitrification and denitrification (SND) under low dissolved oxygen (DO) and anaerobic/aerobic (anoxic) enhanced phosphorus removal (EBPR) are two processes that can significantly reduce the energy and carbon required for nutrient removal. The combination of the two processes is expected to achieve biological nutrient removal with minimal requirement of oxygen and carbon. In this study, a lab-scale sequencing batch reactor (SBR) was operated to perform simultaneous nitrification and denitrification as well as phosphorus removal (SNDPR) with micro aeration. The EBPR system showed a high phosphorus removal efficiency (phosphate in effluent $<0.5 \mathrm{mg} / \mathrm{L}$ ) and complete ammonia oxidation without accumulation of nitrite and nitrate under low dissolved oxygen (DO) concentration (controlled at $0.2 \mathrm{mg} / \mathrm{L}$ ). Regular operation and batch test demonstrated that the sludge was capable of using nitrite as electron acceptor to take up phosphate, the maximum specific denitrifying phosphorus uptake rates of adding $10 \mathrm{mg} / \mathrm{L}$ and 50 $\mathrm{mg} / \mathrm{L} \mathrm{NO}_{2}{ }^{-} \mathrm{N}$ to maximum specific aerobic phosphorus uptake rate were $44.9 \%$ and $87.2 \%$, respectively. Moreover, batch tests suggested that ammonia nitrogen was removed through simultaneous nitrification and denitrification rather than anaerobic ammonium oxidation, whereas ammonia oxidized bacteria ( $\mathrm{AOB}$ ) and nitrite oxidized bacteria (NOB) were found to be less active than PAOs under low DO environment.

\section{Introduction}

Enhanced biological phosphorus removal (EBPR) has been applied for decades to economically remove wastewater effluent phosphorus compared with chemical treatment methods. Polyphosphate-accumulating organisms (PAOs), which are responsible for EBPR, are capable of accumulating polyphosphate as an intracellular storage compound using oxygen as an electron acceptor and enriched through alternating anaerobic-oxic cycles [1 3]. However, EBPR combined with biological nitrogen removal processes have a drawback for deficient carbon source in the incoming wastewater, which is often the limiting factor for phosphorus release and denitrification.

Studies have been showing that the so-called denitrifying PAOs (DPAOs) is capable of utilizing nitrate/nitrite instead of oxygen as an electron acceptor for phosphorus uptake [4,5]. The use of DPAOs in biological nutrient removal (BNR) processes is highly beneficial because the same organic substrate can be efficiently used as energy source for both nitrogen and phosphorus removals. Other advantages associated with DPAO activity include a reduction in aeration cost and sludge production [6,7]. Through molecular techniques, an uncultured organisms related to Candidatus Accumulibacter phosphatis (henceforce referred to as Candidatus Accumulibacter) are frequently identified as the major PAOs in lab-scale EBPR systems and some full-scale EBPR 
facilities [8 10]. Kim et al., however, recently reported that the Candidatus Accumulibacter cells lack nitrate reduction capabilities and that phosphate uptake by Candidatus Accumulibacter was dependent upon nitrite generated by associated nitrate-reducing bacteria such as Dechloromonas and Candidatus Competibacter [11].

Furthermore, nitrogen removal via simultaneous nitrification and denitrification (SND) under lower DO conditions has been recognized as one strategy for saving energy consumption (low oxygen supply) in biological wastewater treatment process [12 14]. Additionally, nitrogen removal has been reported to be accomplished by partial oxidation of ammonium to nitrite, which is then directly reduced to nitrogen gas [15]. This process, termed SND via nitrite, saves $40 \%$ of the COD requirement compared with conventional denitrification via nitrate. It has also been reported to achieve higher denitrification rates and a lower biomass yield during aerobic growth [16].

In the ideal case, more organic substrate and energy could be saved if nitrogen and phosphorus removal could be accomplished through SNDPR under low DO. This study aims to demonstrate a process and enrich biomass with the capability of simultaneous nitrogen and phosphorus removal in a lab-scale sequencing batch reactor (SBR) under alternating anaerobic/aerobic condition with micro aeration. Batch experiments are conducted to investigate the possible biochemical reactions and elucidate the functional bacteria responsible for nitrogen and phosphorus removal.

\section{Materials and Methods}

Reactor Setup and Operation. The SBR with a working volume of $2 \mathrm{~L}$ was seeded with sludge from the Nine Springs Wastewater Treatment Plant (Wisconsin, the United States), which performs a stable nitrogen and phosphorus removal with UCT process. The SBR was operated with a cycle time of $8 \mathrm{~h}$ controlled at a room temperature $\left(22^{\circ} \mathrm{C}\right)$. Each cycle consisted of an anaerobic phase, an anoxic phase and/or an aerobic phase, followed by 50-min settling and 10-min decanting. During the aerobic period, air was delivered intermittently using an on/off control system to keep the DO level at $0.2 \mathrm{mg} / \mathrm{L}$. After settling period, $670 \mathrm{~mL}$ of clarified supernatant was removed and an equal volume of synthetic wastewater was pumped into the reactor at the beginning of the next cycle. The sludge retention time was maintained at approximately 80 days by withdrawing a small portion of sludge from the reactor. In addition, the $\mathrm{pH}$ of the mixed liquor was maintained between 7.0 and 7.5 by adding acid using an automated $\mathrm{pH}$ controller (Cole Palmer, Vernon Hills, Ill.).

The SBR operation was gradually acclimated from anaerobic/oxic (An/O) to anaerobic/anoxic/oxic $(\mathrm{An} / \mathrm{Ax} / \mathrm{O})$, then to anaerobic/oxic $(\mathrm{An} / \mathrm{O})$ by adjusting nitrite addition time during three experimental stages. During stage 1, nitrite was added at the beginning of aerobic phase to obtain low DO nitrification. In stage 2, nitrite was spiked into the reactor at the beginning of the anoxic phase to induce denitrifying phosphorus removal. In stage 3, nitrite was removed to achieve simultaneous nitrification and denitrifications coupled with phosphorus removal at low DO.

The synthetic wastewater was prepared to have chemical oxygen demand (COD), nitrogen and phosphorus concentrations of 200-500 mg COD/L, $23.5 \mathrm{mg} \mathrm{NH}_{4}{ }^{+} \mathrm{-N} / \mathrm{L}$ and $9.2 \mathrm{mg} \mathrm{PO}_{4}{ }^{3-}-\mathrm{P} / \mathrm{L}$, respectively. To simulate the desired strength, two autoclaved concentrated solutions (Feed $\mathrm{A}$ and Feed B) were mixed with deionized water directly in the SBR reservoirs. During a feeding step, the reactors received $604 \mathrm{~mL}$ of deionized water plus $33 \mathrm{~mL}$ of each feed solution. Feed A contained (per liter) $5.24 \mathrm{~g}$ or $13.1 \mathrm{~g}$ sodium acetate, $0.88 \mathrm{~g} \mathrm{KH}_{2} \mathrm{PO}_{4}, 9.1 \mathrm{~g} \mathrm{NaHCO}_{3}$, and $0.68 \mathrm{~g} \mathrm{KHSO}_{4}$. The composition of Feed $\mathrm{B}$ was (per liter) $1.96 \mathrm{~g} \mathrm{NH}_{4} \mathrm{Cl}, 4.44 \mathrm{~g} \mathrm{CaCl}_{2} \cdot 2 \mathrm{H}_{2} \mathrm{O}, 3.03 \mathrm{~g} \mathrm{MgSO}_{4}$ [17] and 20 $\mathrm{mL}$ of a trace element solution. The trace element solution was based on the one used by 
Hesselmann et al. [8] and contained (per liter) $5.51 \mathrm{~g}$ citric acid, $4.03 \mathrm{~g}$ hippuric acid, $0.73 \mathrm{~g}$ $\mathrm{Na}_{3}$ NTA. $\mathrm{H}_{2} \mathrm{O}, 0.3 \mathrm{~g} \mathrm{Na}$ EDTA. $4 \mathrm{H}_{2} \mathrm{O}, 3.03 \mathrm{~g} \mathrm{FeCl}_{3} \cdot 6 \mathrm{H}_{2} \mathrm{O}, 0.5 \mathrm{~g} \mathrm{H}_{3} \mathrm{BO}_{3}, 0.3 \mathrm{~g} \mathrm{ZnSO} \cdot 7 \mathrm{H}_{2} \mathrm{O}, 0.24 \mathrm{~g}$ $\mathrm{MnCl}_{2} \cdot 4 \mathrm{H}_{2} \mathrm{O}, 0.12 \mathrm{~g} \mathrm{CuSO}_{4} \cdot 5 \mathrm{H}_{2} \mathrm{O}, 0.06 \mathrm{~g} \mathrm{KI}, 0.06 \mathrm{~g} \mathrm{Na}_{2} \mathrm{MoO}_{4} \cdot 2 \mathrm{H}_{2} \mathrm{O}, 0.06 \mathrm{~g} \mathrm{CoCl}_{2} \cdot 6 \mathrm{H}_{2} \mathrm{O}, 0.06 \mathrm{~g}$ $\mathrm{NiCl}_{2} \cdot 6 \mathrm{H}_{2} \mathrm{O}$ and $0.06 \mathrm{~g} \mathrm{Na}_{2} \mathrm{WO}_{4} \cdot 2 \mathrm{H}_{2} \mathrm{O}$. A nitrite stock solution was prepared by adding $9.8572 \mathrm{~g}$ of $\mathrm{NaNO}_{2}$ in $1 \mathrm{~L}$ of deionized water (resulted in the nitrite concentration of $2000 \mathrm{mg} \mathrm{NO}{ }_{2}^{-}-\mathrm{N} / \mathrm{L}$ ).

Batch Tests. A series of batch experiments were performed with the running SBR system during steady state under different operating stages. The methods and materials are described below.

Typel: Nitrite and ammonia consumption in the absence of DO. During stage 1 (day 23), 10 $\mathrm{mL}$ of nitrite solution was spiked into the reactor, resulting in a nitrite concentration of $10 \mathrm{mg}$ $\mathrm{NO}_{2}{ }^{-}$-N/L. During stage 3 (day 164), $5 \mathrm{~mL}$ of nitrite solution was spiked into the reactor after complete phosphorus uptake under low DO condition. The aim of these batch experiments was to investigate whether anaerobic ammonium oxidation (ANAMMOX) occurred in the reactor or not.

Type II: Phosphate uptake under anoxic and micro ae robic conditions. During stage 2 (day 88), the sludge was divided evenly into three jars after anaerobic period. And, the three jars were supplied with nitrite of $10 \mathrm{mg} \mathrm{NO}_{2}{ }^{-} \mathrm{N} / \mathrm{L}, 50 \mathrm{mg} \mathrm{NO}{ }^{-}-\mathrm{N} / \mathrm{L}$ and air(DO controlled @ $0.2 \mathrm{mg} / \mathrm{L}$ ), respectively. The motivation of the batch tests was to confirm the possible ways of nitrite consumption through DPAOs and investigate the phosphorus removal performance under low DO.

Type III: Nitrification of ammonia and nitrite under high DO. During stage 3 (day 157), air was supplied with DO controlled at $5 \mathrm{mg} / \mathrm{L}$ instead of $0.2 \mathrm{mg} / \mathrm{L}$ after anaerobic phase. On day 163 , after the completion of phosphorus uptake and ammonia oxidation, $5 \mathrm{~mL}$ of nitrite solution was spiked into the reactor and DO was also controlled at $5 \mathrm{mg} / \mathrm{L}$. The tests were performed to detect the ammonia oxidized bacteria (AOB) and nitrite oxidized bacteria (NOB) activity in the reactor.

Sampling and analy tical methods. Effluent of the SBR and an activated sludge was sampled every 2 day for chemical analysis and concentration measurement. When the SBR operation reached a steady state, a track analysis of an entire cycle was carried out. The mixture of liquor samples $(8 \mathrm{~mL})$ was withdrawn from the reactor during the operating cycle at some special points. Once the sample was withdrawn from the reactor, it was immediately centrifuged at a $3000 \mathrm{r} / \mathrm{min}$ for 2 min and filtered through a $0.45 \mu \mathrm{m}$ filter paper.

Concentrations of soluble inorganic phosphate, COD and ammonia was analyzed by Phos Ver 3, Hach's low range COD and salicylate method using a Test N' Tube kit (Hach, Loveland, Co.), respectively. Acetate, nitrite and nitrate were regularly monitored by a Shimadzu high performance liquid chromatography (Kyoto, Japan) equipped with an Alltech Previal Organic Acid Column (Deerfield, Illinois) and a photodiode array detector set at 210 and $214 \mathrm{~nm}$. Total suspended solids (TSS) and volatile suspended solids (VSS) were measured according to Standard Methods[18]. DO and $\mathrm{pH}$ were measured online using DO and $\mathrm{pH}$ sensors (WTW 340i, WTW Company, Germany), respectively.

\section{Results and Discussion}

SNDPR performance of the running SBR in different stage. Fig. 1 shows the nutrient removal and sludge performance of the SBR as well as the measured profiles of chemicals during a typical cycle of each operational stage. The controlled level of dissolved oxygen was set as $0.2 \mathrm{mg} / \mathrm{L}$ during the aerobic periods, resulting in the highest DO level of $0.4 \mathrm{mg} / \mathrm{L}$. From Fig. 1A and Fig. 1 B, total nitrogen could not be removed completely in stage 1, although DO level was controlled at a low condition under which SND was easily achieved. In addition, phosphorus removal performance deteriorated rapidly for several days, implying PAOs were washed out from the system due to the 
limited carbon source in influent. During the aerobic phase in the first stage (Fig. 1D), ammonia and nitrite were completely oxidized with a minimum aeration. However, significant phosphate release and uptake activity was not observed, indicating a limited amount of PAOs in the system.
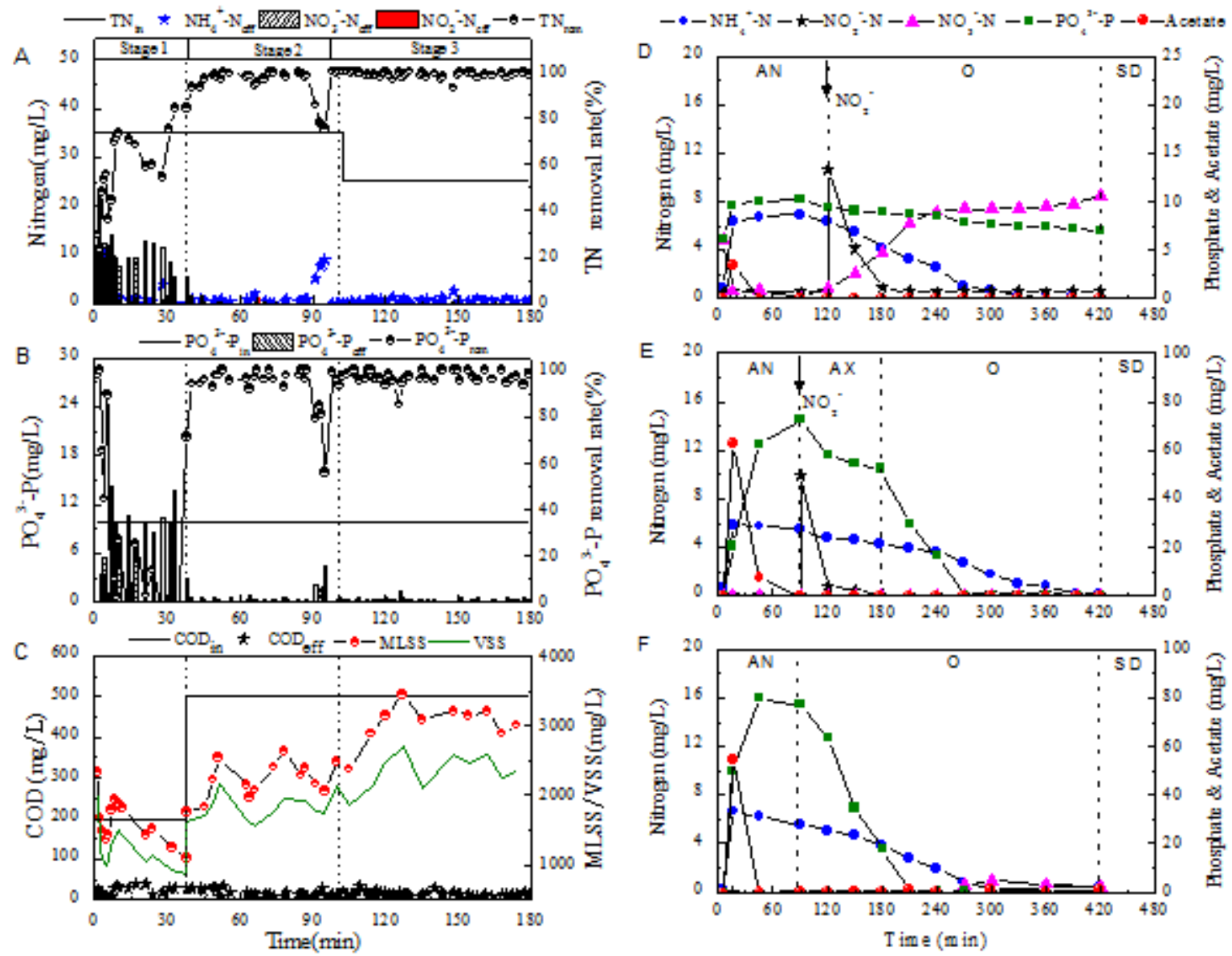

Fig. 1 SNDPR performance of the running SBR (A, B, C) and profiles of ammonia, nitrite, nitrate, phosphate and acetate during a typical cycle of each stage. The profiles were obtained from stage 1 (D, day 7), stage 2(E, day 78) and stage 3 (F, day 123) shown in Table 1. AN, AX, O and SD represent anaerobic, anoxic, aerobic, and settling and decanting phase, respectively.

In order to increase the population of PAOs, new sludge drawn from Nine Springs WWTP was added into the reactor. The amount of the new sludge supplied covered $55 \%$ of the final total sludge in the reactor. Anoxic period was also introduced into the operational process and nitrite was added to induce anoxic phosphorus uptake. Moreover, influent COD was increased to enhance anaerobic phosphate release. As a result, phosphorus and nitrogen were removed with only small amount of nitrogen oxides accumulation (Fig1 A, 1B). It also can be seen from Fig.1E that phosphate uptake and nitrite reduction occurred concurrently, which means nitrite was utilized by DPAOs as electron acceptor in anoxic period. The slower phosphate uptake tendency indicates the depletion of nitrite. During the aerobic period, phosphate uptake reoccurred and phosphate uptake rate was greater than that of anoxic period. Ammonia was completely oxidized without nitrite or nitrate accumulation.

In stage 3, nitrite was removed to save cost since phosphate uptake could be accomplished under such a low DO condition. Fig. $1 \mathrm{~F}$ is the profile of various chemicals during stage 3 . The results showed that both phosphorus and nitrogen were removed with a minimum residue (less than $0.5 \mathrm{mg} / \mathrm{L}$ ) under low DO condition. It is noted from Fig. 1E and Fig. 1F that the occurrence of phosphorus uptake was always prior to the oxidation of ammonia, which is not in accordance with 
the literature reported [19]. Besides, DO didn't show an increase $(<0.05 \mathrm{mg} / \mathrm{L})$ until complete phosphate uptake was achieved (data not shown). The observations indicate the denitrification was not carried out by DPAOs. Fig. 1C shows the sludge performance of different stage. The biomass kept relatively stable and increased during stage 2 and 3 except for a rapid sludge loss observed at the very beginning of stage 1 due to sludge bulking of the abrupt low DO environment.

Study on possible biological activities under different stages. In order to further understand the possible biological activities under different stages, a series of batch tests were performed to assess the performance of nitrification, denitrification, aerobic phosphate uptake, anoxic phosphate uptake and even anaerobic ammonia oxidation.

Consumption of nitrite and ammonia without oxygen. A total nitrogen loss was observed during the low DO aerobic phase of the typical cycles (Fig.1). Two batch tests were performed to investigate if ANAMMOX occurred in the reactor. The results obtained from the two studies are shown in Fig. 2.
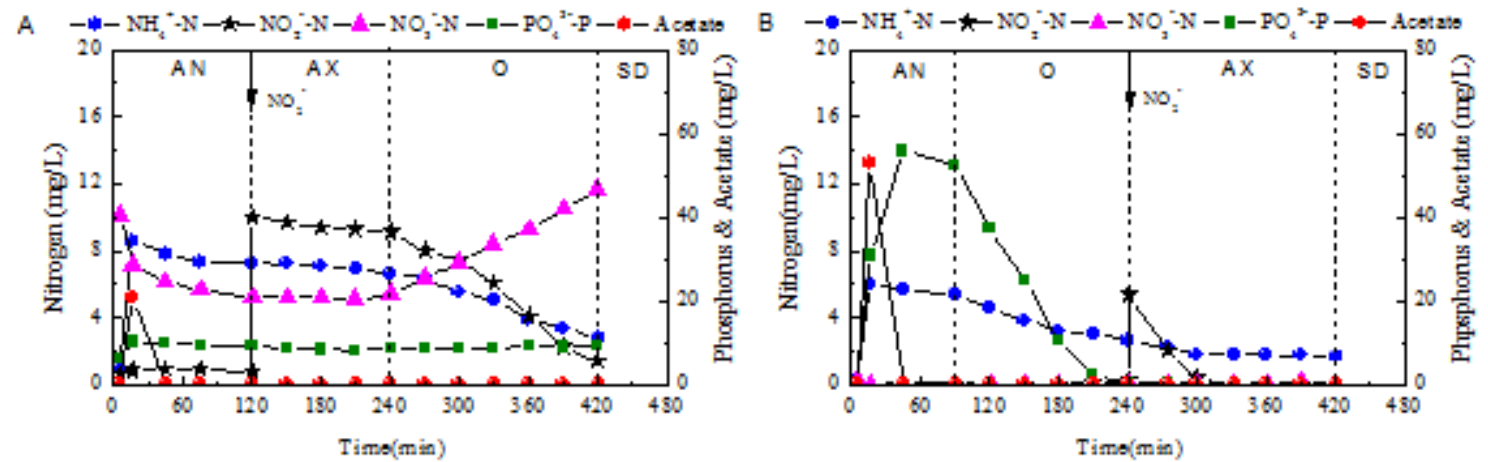

Fig. 2 Nitrite and ammonia consumption without oxygen. The tests were performed on day 23(A) and 164(B) during stage 1 and 3, respectively.

It is noted from Fig. 2A that the concentrations of nitrite and ammonia had no significant change during the anoxic period. Instead, ammonia and nitrite was oxidized and nitrate accumulation was observed in the subsequent aerobic phase. In Fig. 2B, nitrite was injected into the reactor after the complete aerobic phosphate uptake to avoid the competition of nitrite by DPAOs and NOB. After, air was removed from the reactor. During the anoxic phase, nitrite was consumed quickly, whereas ammonia consumption was not observed. From those findings above, it is further verified that ammonia was removed through SND throughout the three operational stages.

Nitrite-type anoxic phosphate uptake and micro ae robic phosphate uptake. The specific phosphate uptake with nitrite and oxygen under low DO in the SBR was shown in Fig. 3. Although anoxic phosphate uptake activity is known to be slower than that of aerobic condition, a small discrepancy of these two specific phosphate uptake rates were observed in this study, implying the dominance of DPAOs in the EBPR system. Zhou reported nitrite or the protonated form of nitrite, free nitrous acid (FNA) had a severe inhibitory effect on the metabolism of bacteria involved in nitrogen and phosphorus removal. The reported FNA concentration inhibiting DPAOs by $50 \%$ is $0.01 \mathrm{mgHNO}_{2}-\mathrm{N} / \mathrm{L}\left(45 \mathrm{mgNO}_{2}{ }^{-} \mathrm{N} / \mathrm{L}\right.$ at $\mathrm{pH}$ 7.0) [20]. In this study, however, nitrite was completely consumed by DPAOs even with a high loading of $50 \mathrm{mg} \mathrm{NO}{ }_{2}^{-}-\mathrm{N} / \mathrm{L}$, which was accompanied by the uptake of phosphate. The specific phosphate uptake rate(SPUR) was $87.2 \%$ of aerobic specific phosphate uptake rate and was nearly two times of that with $10 \mathrm{mg} \mathrm{NO}_{2}^{-}-\mathrm{N} / \mathrm{L}$ (SPRU was $44.9 \%$ of aerobic specific phosphate uptake rate). These results suggest that nitrite might be the real electron acceptor instead of an inhibitor of PAOs, which agrees with a previous study that the genome of Candidatus Accumulibacter encode the nitrite reductase [21]. Once nitrite depleted, phosphate 
uptake was no longer observed, indicating the lack of electron acceptor. For the aerobic test, phosphate was completely taken up by PAOs under low DO condition. Meanwhile, a breakthrough of DO was observed, suggesting a decrease of oxygen uptake rate (OUR) of bacteria in the system.

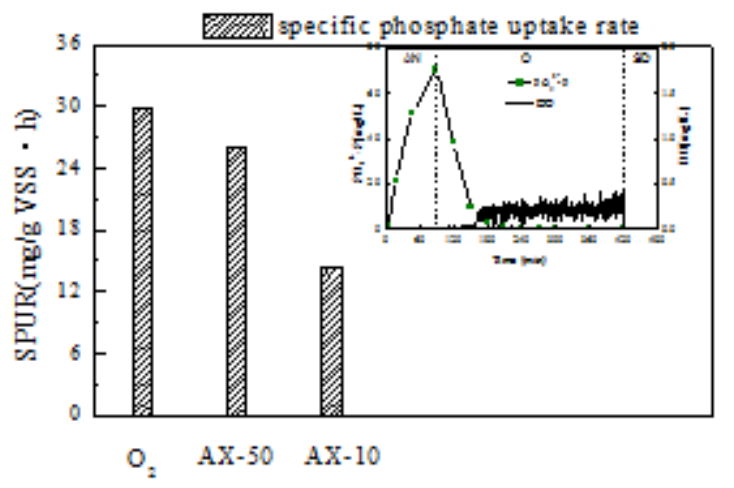

Fig. 3 Specific phosphate uptake under anoxic (with $50 \mathrm{mg} / \mathrm{L}$ or $10 \mathrm{mg} / \mathrm{L} \mathrm{NO}_{2}{ }^{-}-\mathrm{N}$ addition) and aerobic conditions during stage 2(day 88).

Nitrification of ammonia and nitrite under high DO. Although ammonia has been confirmed to be removed through SND, the organisms responsible for nitrification are still unknown.
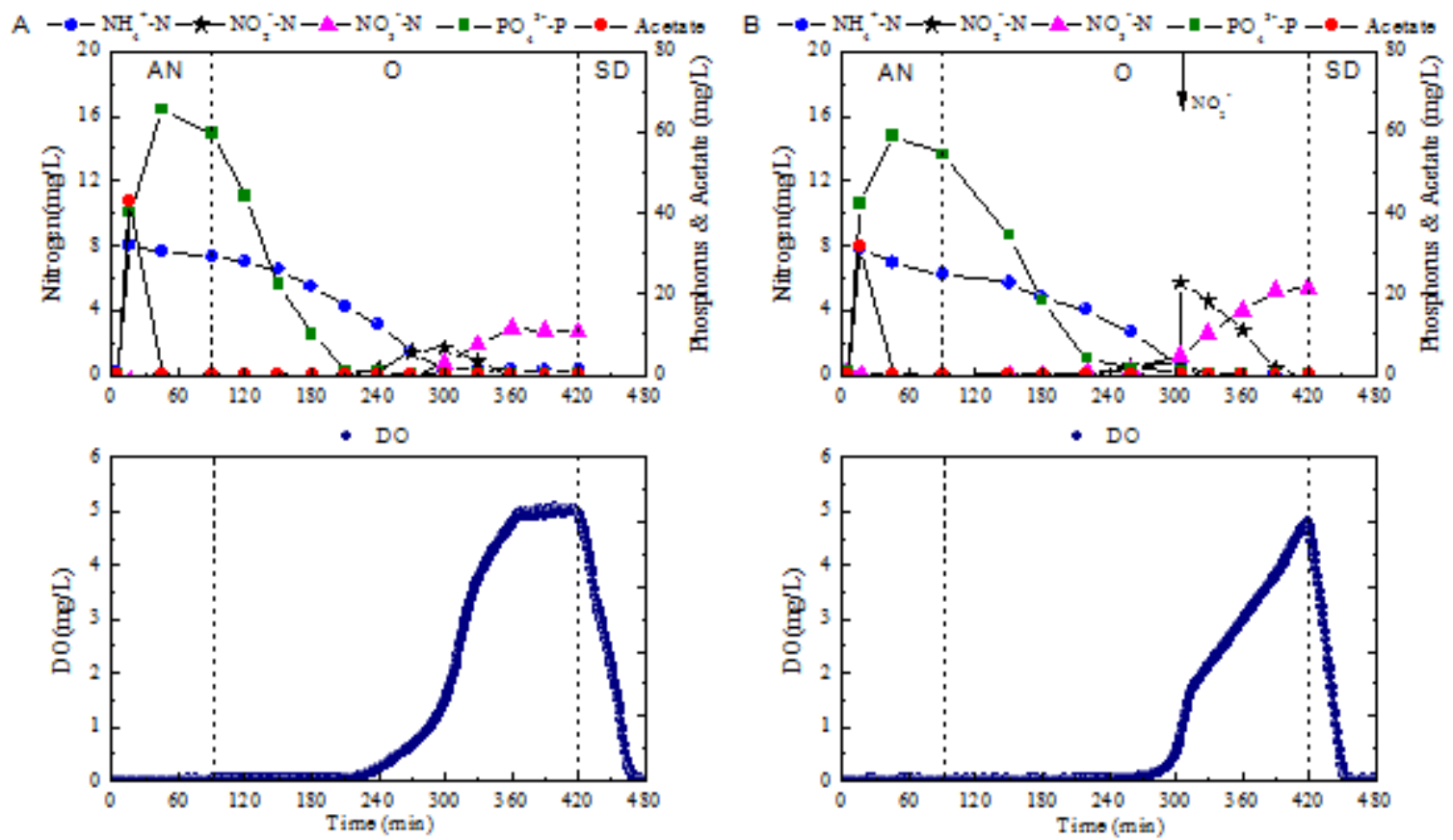

Fig. 4 Ammonia and nitrite oxidation under high DO conditions after complete phosphate uptake. The experiments were conducted on day 157(A) and 163 (B), respectively, during stage 3.

In the process of shortcut nitrogen removal, NOB could be gradually washed out from system due to the unfavorable environment like low DO [22]. From Fig. 4A, however, nitrite was found to be accumulated and finally oxidized to nitrate when DO was highl. In Fig. 4B, nitrate accumulation was also observed after nitrite added. The results further confirm the fact that ammonia in influent was removed through nitrate rather than nitrite way, which is a coincidence with nitrate accumulated during aerobic phase in stage 3 (see Fig. 1F). Therefore, AOB couldn't outcompete NOB in the low DO system, which is in accordance with the result of NOB enriched successfully with AOB at very low oxygen concentration [23]. DO was only one of the key factors in SND of the reactor. Additionly, it should be noted that phosphate uptake occurred first even DO was 
controlled at a high level of $5 \mathrm{mg} / \mathrm{L}$, which can be explained by the fact of very low DO condition before the completion of phosphate uptake. In other words, PAOs consumed the oxygen supplied very quickly so that no additional oxygen could be used by the nitrifiers. Thus, the activity of AOB and NOB becomes very low when they have to compete for oxygen with the PAOs. Nevertheless, the reason why phosphate was taken up first under low DO condition requires further investigation.

\section{Conclusions}

(1) Nitrogen and phosphorus could be removed simultaneously without nitrite and nitrate accumulation in the system. Phosphate uptake always occurred prior to ammonia oxidation during the aerobic period due to the competition of oxygen between PAOs and nitrifiers under low DO conditions.

(2) Efficient phosphate uptake could occur under both nitrite and low DO conditions as long as the electron acceptor was sufficiently supplied. Thus, simultaneous nitrogen and phosphorus removal could be achieved in both continuous and intermittent flow processes with low DO aerobic phase.

(3) NOB couldn't be washed out under low DO condition. Nitrogen removal was accomplished by SND via nitrate rather than nitrite, though DO in the system was controlled as low as $0.2 \mathrm{mg} / \mathrm{L}$.

\section{Acknowledge ment}

This work was funded by the National Science Foundation under Grant Award (No. 51168027, 51168028) and the Science and Technique Foundation Project of Gansu Province (No. 145RJZA093).

\section{References}

[1] Y. Comeau, K. Hall, R. Hancock, W. Oldham, Biochemical model for enhanced biological phosphorus removal, Wat. Res. 20(1986), 1511-1521.

[2] M. C. Wentzel, R. E. Loewenthal, G. A. Ekama, G. V. Marais, Enhanced polyphosphate organism cultures in activated-sludge systems. 1. Enhanced culture development, Wat. S. A. 14(1988), 81-92.

[3] T. Mino, M. C. M. van Loosdrecht, J. J. Heijnen, Microbiology and biochemistry of the enhanced biological phosphate removal process, Wat. Res. 32(1998), 3193-3207.

[4] J. P. Kerrn-Jespersen, M. Henze, Biological phosphorus uptake under anoxic and aerobic conditions, Wat. Res. 27(1993), 617-624.

[5] T. Kuba, G. J. F. Smolders, M. C. M. van Loosdrecht, J. J. Heijnen, Biological phosphorus removal from wastewater by anaerobic and anoxic sequencing batch reactor, Wat. Sci. Technol. 27(1993), 241-252.

[6] T. Kuba, A. Wachtmeister, M. C. M. van Loosdrecht, J. J. Heijnen, Effect of nitrate on phosphorus release in biological phosphorus removal systems, Wat. Sci. Technol. 30(1994), 263-269.

[7] E. Murnleitner, T. Kuba, M. C. M. van Loosdrecht, J. J. Heijnen, An integrated metabolic model for the aerobic and denitrifying biological phosphorus removal, Biotechnol. Bioeng. 54(1997), 
434-450.

[8] R. P. X. Hesselmann, C. Werlen, D. Hahn, J. R. van der Meer, A. J. B. Zehnder, Enrichment, phylogenetic analysis and detection of a bacterium that performs enhanced biological phosphate removal in activated sludge, Syst. Appl. Microbiol. 22(1999), 454-465.

[9] J. L. Zilles, J. Peccia, M. W. Kim, C. H. Hung, D. R. Noguera, Involvement of Rhodocyclus-related organisms in phosphorus removal in fullscale wastewater treatment plants, Appl. Environ. Microbiol. 68(2002), 2763-2769.

[10] S. He, A. Z. Gu, K. D. McMahon, Progress toward understanding the distribution of accumulibacter among full-scale enhanced biological phosphorus removal systems, Microb. Ecol. 55(2008), $229-236$.

[11] J. M. Kim, H. J. Lee, D. S. Lee, C. O. Jeona, Characterization of the Denitrification-Associated Phosphorus Uptake Properties of "Candidatus Accumulibacter phosphatis" Clades in Sludge Subjected to Enhanced Biological Phosphorus Removal, App. Environ. Microbiol. 79(2013), 1969-1979.

[12] E. von Münch, P. Lant, J. Kelle, Simultaneous nitrification and denitrification in bench-scale sequencing batch reactors, Wat. Res. 30(1996), 277-284.

[13] G. Bertanza, Simultaneous nitrification-denitrification process in extended aeration plants: Pilot and real scale experiences, Wat. Sci. Technol. 35(1997), 53-61.

[14] C. Helmer, S. Kunst, Simultaneous nitrification/denitrification in an aerobic biofilm system, Wat. Sci. Technol. 37(1998), 183-187.

[15] J. Surmacz-Gorska, A. Cichon, K. Miksch, Nitrogen removal from wastewater with high ammonia nitrogen concentration via shorter nitrification and denitrification, Wat. Sci. Technol. 36(1997), 73-78.

[16] O. Turk, D. Mavinic, Preliminary assessment of a shortcut in nitrogen removal from wastewater, Can. J. Civil. Eng. 13(1986), 600-605.

[17] P. L. Bond, R. Erhart, M. Wagner, J. Keller, L. L. Blackall, Identification of some of the major groups of bacteria in efficient and nonefficient biological phosphorus removal activated sludge systems, Appl. Environ. Microbiol. 65(1999), 4077-4084.

[18] APHA, Standard Methods for the Examination of Water and Waste, 18th ed., American Public Health Association, Washington DC, 1998.

[19] R. J. Zeng, R. Lemaire, Z. G. Yuan, J. Keller, Simultaneous Nitrification, Denitrification, and Phosphorus Removal in a Lab-Scale Sequencing Batch Reactor, Biotechnol. Bioeng. 84(2003), 170-178.

[20] Y. Zhou, A. Oehmen, M. Lim, The role of nitrite and free nitrous acid(FNA) in wastewater treatment plants, Wat. Res. 45(2011), 4672-4682.

[21] J. J. Flowers, S. He, S. Yilmaz, D. R. Noguera, K. D. McMahon, Denitrification capabilities of two biological phosphorus removal sludges dominated by different 'Candidatus Accumulibacter' clades, Environ. Microbiol. Rep. 1(2009), 583-588.

[22] Q. Yang, Y. Z. Peng, X. H. Liu, W. Zeng, T. Mino, H. Satoh, Nitrogen removal via nitrite from 
municipal wastewater at low temperatures using real-time control to optimize nitrifying communities, Environ. Sci. Technol. 41(2007), 8159-8164.

[23] H. Park, D. R. Noguera, Nitrospira Community composition in Nitrifying Reactors Operated with Two Diffenren Dissolved Oxygen Levels, J. Microbiol. Biotechnol. 18(2008), 1470-1474. 